\title{
Identification of Candidate Genes in Early-Stage Invasive Ductal Carcinoma Patients with High-Risk Mortality using 32 Genes Commonly Involved in Breast Cancer: A Retrospective Study
}

\author{
Chih-Chiang Hung \\ Taichung Veterans General Hospital \\ Hsin-I Huang \\ E-Da Cancer Hospital \\ SIN HUA MOI ( $\square$ moi9009@gmail.com ) \\ E-Da Cancer Hospital https://orcid.org/0000-0002-4082-1909
}

\section{Primary research}

Keywords: Early breast cancer, Invasive ductal carcinoma, Survival analysis, Gene mutation

Posted Date: July 14th, 2020

DOI: https://doi.org/10.21203/rs.3.rs-41002/v1

License: (c) (1) This work is licensed under a Creative Commons Attribution 4.0 International License.

Read Full License

Version of Record: A version of this preprint was published at Public Health Genomics on October 11th, 2021. See the published version at https://doi.org/10.1159/000519140. 


\section{Abstract}

Background: Invasive ductal carcinoma (IDC) breast cancer is a heterogeneous disease characterized by multiple subtypes. Breast cancer survival is highly impacted by tumor burden, molecular subtypes, and gene profiles. Gene mutation is a type of genomic instability regarded as having a considerable effect on breast cancer prognosis. Using integrated survival analysis, this study identified candidate genes and a high-risk group of patients with early-stage IDC breast cancer to provide further understanding of the genetic characteristics associated with poor survival.

Methods: The gene mutation profiles, baseline demographics, clinicopathological variables, and treatment characteristics of the early-stage breast cancer subpopulation were downloaded from an open access data platform. These data were analyzed for a total of 444 patients. In total, 32 genes commonly involved in breast cancer were listed, and the genes exhibiting significant differences (as estimated using the log-rank test) were selected as the candidate genes.

Results: The patients were divided into control, low-risk, and high-risk groups according to their gene mutation profiles. The 5-year overall survival rates were $97.6 \%, 96.0 \%$, and $68.2 \%$, respectively. The highrisk group had a significantly higher risk of poor overall survival (adjusted hazard ratio $=9.94,95 \%$ confidence interval $=2.24-44.20, P=0.003$ ) than the other groups and the low-risk group did not have a significantly higher risk of poor overall survival compared with controls.

Conclusions: This study proposed an integrative approach for the identification of candidate genes for risk assessment of overall survival in these patients through typical survival analysis methods. The 10 candidate genes selected are particularly involved in cell-cycle processes, DNA repair, and drug resistance; their mutations were found to be generally associated with disease progression or therapeutic resistance, which is commonly associated with poor survival outcomes.

\section{Background}

Invasive ductal carcinoma (IDC), which accounts for approximately $65-85 \%$ of breast cancer cases, is a heterogeneous disease characterized by multiple subtypes [1]. Studies have demonstrated that the treatment options, prognosis, and survival outcomes of breast cancer are highly affected by tumor burden, molecular subtypes, and gene profiles [2-5]. Gene mutations also play a crucial role in characterizing the tumor burden and molecular subtypes. For instance, the human epidermal growth factor receptor 2 (HER2)-enriched subtype of breast cancer is characterized by HER2/ERBB2 mutations, and circulating tumor deoxyribonucleic acid (DNA) can be used to monitor tumor burden in breast cancer $[6,7]$.

Gene mutations are a type of genomic instability considered to have a considerable effect on breast cancer prognosis [8]. Because gene mutations in breast cancer are very broad in scope, identifying all of the related genes is difficult [9]. Therefore, the genes previously reported to be involved in IDC breast cancer were considered appropriate target genes in evaluating the effects of gene mutation on overall 
survival. For instance, common genes involved in breast cancer including TP53, HER2/ERBB2, CCND1, EMSY, FGFR1, BRCA1, BRCA2, BRCA3, PTEN, ATM, MSH2, MLH1, PMS1, MSH3, CDH1, HRAS, NRAS, and KRAS have often been discussed in the literature [10, 11]. Moreover, BIRC5, EGFR, ESR1, HIF1A, IGF1R, MYC, NOTCH1, PIK3CA, PTEN, RARB, RASSF1, SRC, TOP2A, and TWIST1 have been noted to be involved in breast cancer progression [8, 12-15].

Overall survival is considered a suitable endpoint for the evaluation of risk characteristics in patients with cancer [16]. The Kaplan-Meier estimator with the log-rank test and the Cox proportional hazard regression model testing are methods typically used for analyzing overall survival. They are based on a time-to-event $=$ model and have been widely used in cancer research $[17,18]$. The Kaplan-Meier estimator and log-rank test methods provide reliable results for single-variable risk assessment of overall survival [18]. The Cox proportional hazard regression model can singly or partially assess the effect of both single and multiple variables on overall survival [17].

Most research thus far has focused on a single gene or the effect of a specific gene function on breast cancer survival outcomes. An integration method for identification of candidate genes associated with poor survival is required to better understand the effects of gene mutation on overall survival. Typically, clinicians are more familiar with survival analysis methods than complex machine learning methods. Although multiple machine learning algorithms have provided precise and efficient analyses, using these algorithms is not necessarily worthwhile due to the long running time and the computational complexityparticularly for cases with only slight improvement. Therefore, in this study, we used an integrative approach involving typical survival analysis methods to identify candidate genes in patients with earlystage IDC breast cancer. This study aimed to achieve further understanding of the genetic characteristics associated with poor survival outcomes in breast cancer.

\section{Methods And Materials}

\section{Dataset}

The gene mutation profiles (i.e., the mutation data for breast cancer from the MuTect2 pipeline) and clinical information were downloaded from the Genomic Data Commons data portal using the TCGAbiolinks package, an R/Bioconductor package for integrative analysis of the Cancer Genome Atlas data The patient inclusion criteria were as follows: (1) women; (2) diagnosis of pathologic stage I, II or III breast cancer, (3) specifically IDC; and (4) estimable survival status and follow-up interval. A total of 444 patients were included for analysis. Age at diagnosis, race and ethnicity were included as baseline demographics. Age at diagnosis was categorized as $<35,35-50$, and $>50$ years. Others prognostic variables, including breast cancer subtypes, pathologic stage, and treatment characteristics, were also included in later analysis.

\section{The 32 genes commonly involved in breast cancer and gene mutation risk groups}


In total, 32 genes commonly involved in breast cancer, namely TP53, HER2/ERBB2, CCND1, FGFR1, BRCA1, BRCA2, BRCA3, PTEN, ATM, MSH2, MLH1, PMS1, MSH3, CDH1, HRAS, NRAS, KRAS, BIRC5, EGFR, EMSY, ESR1, HIF1A, IGF1R, MYC, NOTCH1, PIK3CA, PTEN, RARB, RASSF1, SRC, TOP2A, and TWIST1, were compiled into a list [10]. The gene mutation profile of each patient was matched with the genes on the list. The gene mutation status of each patient was determined based on matching results between the gene list and patient's gene mutation profile. Afterward, survival analysis was used to evaluate the effect of the gene mutation statuses on overall survival. Ten involved genes that displayed significant survival differences between patients who alive and dead were selected as the candidate genes. The patients who had no mutations in any of the 32 genes on the list were defined as controls. According to gene mutation status, the remaining patients were divided into low-and high-risk groups. Patients with mutations in the candidate genes were placed into the high-risk group, and the others were assigned to the low-risk group.

\section{Statistical analysis}

The baseline demographics, clinicopathological variables, treatment characteristics, and overall survival outcomes of the study population are presented as frequencies and percentages, and the distribution differences in between the control, low-risk, and high-risk groups were estimated using the chi-square test or Fisher's exact test, as appropriate. The mutation rates of the 32 genes in the patients were determined, and the differences in overall survival by mutation rate were estimated using the log-rank test. The genes that displayed significant differences in survival between the patients with and without mutations in the candidate genes were included in the high-risk gene set. The Kaplan-Meier curve was used to illustrate the differences in overall survival by risk category and single gene mutation status. Cox proportional hazard regression analysis was performed to estimate the effect of gene mutation risk score and covariates on overall survival. All factors were included in the multivariate model. All $P$ values were twosided and the statistical significance was set at 0.05. All analyses were conducted using version 4.0.1 of the computing environment R (R Core Team, 2020).

\section{Results}

\section{Patient characteristics}

Baseline demographics, clinicopathological variables, and treatment characteristics of the study population are summarized in Table 1. At a median follow-up of 2.2 years (range 1.2-23.4), 16 all-cause deaths (3.6\%) had occurred. The study population had a higher proportion of patients who were aged 35-50 years (431; 97.1\%), were Caucasian (69.1\%), and not Hispanic or Latino (77.7\%). The study population was more likely to have been diagnosed as having the luminal A or normal-like $(191 ; 43.0 \%)$ and luminal B (110; 24.8\%) molecular subtypes of breast cancer. The basal-like subtype was observed in 101 (22.7\%) patients and HER-2 overexpression was observed in 42 (9.5\%) of patients. In treatment characteristics, 243 (54.7\%) patients had received radiation treatment and $363(81.8 \%)$ patients had received pharmaceutical treatment. 
Table 1

Baseline demographics and clinicopathological variables of patients with early-stage IDC breast cancer $(\mathrm{N}=444)$.

\begin{tabular}{|c|c|}
\hline Variables & Overall, $n=444$ \\
\hline \multicolumn{2}{|l|}{ Age (years) } \\
\hline$<35$ & $10(2.3 \%)$ \\
\hline $35-50$ & $431(97.1 \%)$ \\
\hline$>50$ & $3(0.7 \%)$ \\
\hline \multicolumn{2}{|l|}{ Race } \\
\hline American Indian or Alaska native & $1(0.2 \%)$ \\
\hline Asian & $36(8.1 \%)$ \\
\hline Black or African American & $56(12.6 \%)$ \\
\hline White & $307(69.1 \%)$ \\
\hline Not reported & $44(9.9 \%)$ \\
\hline \multicolumn{2}{|l|}{ Ethnicity } \\
\hline Hispanic or Latino & $13(2.9 \%)$ \\
\hline Not Hispanic or Latino & $345(77.7 \%)$ \\
\hline Not reported & $86(19.4 \%)$ \\
\hline \multicolumn{2}{|l|}{ Subtypes } \\
\hline Basal-like & $101(22.7 \%)$ \\
\hline HER2-enriched & $42(9.5 \%)$ \\
\hline Luminal A or Normal-like & $191(43.0 \%)$ \\
\hline Luminal B & $110(24.8 \%)$ \\
\hline \multicolumn{2}{|l|}{ Pathological stage } \\
\hline Stage I & $89(20.0 \%)$ \\
\hline Stage II & $273(61.5 \%)$ \\
\hline Stage III & $82(18.5 \%)$ \\
\hline \multicolumn{2}{|l|}{ Treatment characteristics } \\
\hline Radiation & $243(54.7 \%)$ \\
\hline
\end{tabular}




\begin{tabular}{|l|ll|}
\cline { 2 - 3 } & Variables & Overall, $\mathbf{n = 4 4 4}$ \\
\hline Pharmaceutical & $363(81.8 \%)$ \\
\hline All-cause mortality & $16(3.6 \%)$ \\
\hline HER2: human epidermal growth factor receptor 2. \\
\hline \multirow{2}{*}{ Gene mutation profiles }
\end{tabular}

Table 2 presents the mutation rates of the 32 involved genes among the study population by survival outcomes. Mutations in 28 of the 32 involved genes were observed. However, no mutations were found for BRCA3, EMSY, and RASSF1. Figure 1 shows the gene mutation profiles and clinical features for the 308 patients with mutations in the aforementioned 28 genes. Overall, the highest mutation rate was noted for TP53 (0.421) and PIK3CA (0.372), followed by KRAS, MLH1, and MSH2. After the study population was divided into subgroups of patients according to survival status (alive and dead), the logrank test revealed significant differences in survival rate between the patients who had and did not have mutations in the 10 candidate genes: BIRC5, CCND1, ESR1, HRAS, IGF1R, KRAS, MLH1, MSH2, NOTCH1, and $S R C$. These candidate genes had higher mutation rates in the dead patients (Table 2), and the patients with mutations in the candidate genes had a significantly lower survival rate than the patients without mutations in single gene mutations survival analysis (Fig. 2b-k). 
Table 2

Mutation rates of 32 genes commonly involved in breast cancer.

\begin{tabular}{|c|c|c|c|c|}
\hline \multirow[t]{2}{*}{ Gene } & \multicolumn{3}{|c|}{ Mutation rate } & \multirow[t]{2}{*}{$P$} \\
\hline & Overall & Alive & Dead & \\
\hline TP53 & 0.421 & 0.414 & 0.625 & 0.152 \\
\hline HER2/ERBB2 & 0.018 & 0.019 & - & 0.662 \\
\hline CCND1 & 0.002 & - & 0.063 & $<0.001$ \\
\hline FGFR1 & 0.014 & 0.014 & - & 0.705 \\
\hline$B R C A 1$ & 0.023 & 0.023 & - & 0.656 \\
\hline$B R C A 2$ & 0.029 & 0.026 & 0.125 & 0.108 \\
\hline$B R C A 3$ & - & - & - & - \\
\hline PTEN & 0.043 & 0.044 & - & 0.481 \\
\hline ATM & 0.043 & 0.042 & 0.063 & 0.578 \\
\hline $\mathrm{MSH} 2$ & 0.009 & 0.005 & 0.125 & $<0.001$ \\
\hline MLH1 & 0.016 & 0.014 & 0.063 & 0.007 \\
\hline PMS1 & 0.007 & 0.007 & - & 0.725 \\
\hline $\mathrm{MSH} 3$ & 0.014 & 0.012 & 0.063 & 0.072 \\
\hline $\mathrm{CDH1}$ & 0.023 & 0.021 & 0.063 & 0.141 \\
\hline HRAS & 0.002 & - & 0.063 & $<0.001$ \\
\hline NRAS & 0.002 & 0.002 & - & 0.887 \\
\hline$K R A S$ & 0.014 & 0.009 & 0.125 & $<0.001$ \\
\hline BIRC5 & 0.002 & - & 0.063 & $<0.001$ \\
\hline$E G F R$ & 0.027 & 0.023 & 0.125 & 0.232 \\
\hline EMSY & - & - & - & - \\
\hline ESR1 & 0.016 & 0.014 & 0.063 & 0.026 \\
\hline HIF1A & 0.009 & 0.009 & - & 0.711 \\
\hline IGF1R & 0.018 & 0.014 & 0.125 & 0.002 \\
\hline$M Y C$ & 0.002 & 0.002 & - & 0.898 \\
\hline
\end{tabular}

$P$ values were estimated using the log-rank test. 


\begin{tabular}{|lllll|}
\hline Gene & \multicolumn{2}{l}{ Mutation rate } & $P$ \\
\cline { 2 - 5 } & Overall & Alive & Dead & \\
\hline NOTCH1 & 0.014 & 0.009 & 0.125 & $<0.001$ \\
\hline PIK3CA & 0.372 & 0.362 & 0.625 & 0.213 \\
\hline PTEN & 0.043 & 0.044 & - & 0.481 \\
\hline RARB & 0.018 & 0.019 & - & 0.765 \\
\hline RASSF1 & - & - & - & - \\
\hline SRC & 0.009 & 0.007 & 0.063 & 0.002 \\
\hline TOP2A & 0.009 & 0.009 & - & 0.771 \\
\hline TWIST1 & 0.002 & 0.002 & - & 0.910 \\
\hline P values were estimated using the log-rank test. \\
\hline
\end{tabular}

\section{Gene mutation risk groups}

The patients who had no mutations in any of the 32 genes were enrolled as controls. Patients with mutations in BIRC5, CCND1, ESR1, HRAS, IGF1R, KRAS, MLH1, MSH2, NOTCH1, or SRC constituted the high-risk group. The low-risk group consisted of patients with mutations in genes commonly involved in breast cancer but in none of the 10 candidate genes. The between-group survival differences are shown in Fig. 2a. The 5-year overall survival rates of the high-risk, low-risk, and control groups were $68.2 \%, 96.0 \%$ and $97.6 \%$, respectively. The control and low-risk groups had a similar overall survival rate, and the highrisk group had significantly worse survival compared with the two other groups $(P<0.001)$.

Baseline demographics, clinicopathological variables, and treatment characteristics of the control, lowrisk, and high-risk groups are summarized in Table 3. The three groups had similar distributions of age group, race, ethnicity, pathologic stage, and radiation treatment characteristics. With regard to the molecular subtype distribution, the high-risk subgroup had a significantly higher proportion of patients with the luminal B subtype $(29.4 \%$ in controls, $21.7 \%$ in low-risk, $32.3 \%$ in high-risk, $P<0.001)$. Moreover, the high-risk $(64.5 \%, P=0.014)$ group was significantly less likely to receive pharmaceutical treatment than the control $(86.8 \%)$ or low-risk $(81.2 \%)$ groups. The high-risk group had a significantly higher mortality rate (5 deaths; $16.1 \%$ ) than the control (4 deaths; $2.9 \%)$ or low-risk (7 deaths; $2.5 \%$ ) group. 
Table 3

Baseline demographics, clinicopathological variables, and treatment characteristics of gene mutation risk groups in patients with early-stage IDC breast cancer.

\begin{tabular}{|c|c|c|c|c|}
\hline Variables & $\begin{array}{l}\text { Controls, } \\
n=136\end{array}$ & $\begin{array}{l}\text { Low-risk, } \\
n=277\end{array}$ & $\begin{array}{l}\text { High-risk, } \\
\mathrm{n}=\mathbf{3 1}\end{array}$ & $P$ \\
\hline Age (years) & & & & 0.494 \\
\hline$<35$ & $5(3.7 \%)$ & $4(1.4 \%)$ & $1(3.2 \%)$ & \\
\hline $35-50$ & $130(95.6 \%)$ & $271(97.8 \%)$ & 30 (96.8\%) & \\
\hline$>50$ & $1(0.7 \%)$ & $2(0.7 \%)$ & - & \\
\hline Race & & & & 0.141 \\
\hline American Indian or Alaska native & - & $1(0.4 \%)$ & - & \\
\hline Asian & $5(3.7 \%)$ & $27(9.7 \%)$ & $4(12.9 \%)$ & \\
\hline Black or African American & $24(17.6 \%)$ & $30(10.8 \%)$ & $2(6.5 \%)$ & \\
\hline White & $92(67.6 \%)$ & $192(69.3 \%)$ & $23(74.2 \%)$ & \\
\hline Not reported & $15(11 \%)$ & $27(9.7 \%)$ & $2(6.5 \%)$ & \\
\hline Ethnicity & & & & 0.741 \\
\hline Hispanic or Latino & $5(3.7 \%)$ & $7(2.5 \%)$ & $1(3.2 \%)$ & \\
\hline Not Hispanic or Latino & $101(74.3 \%)$ & $220(79.4 \%)$ & $24(77.4 \%)$ & \\
\hline Not reported & $30(22.1 \%)$ & $50(18.1 \%)$ & $6(19.4 \%)$ & \\
\hline Subtypes & & & & $<0.001$ \\
\hline Basal-like & $14(10.3 \%)$ & $81(29.2 \%)$ & $6(19.4 \%)$ & \\
\hline HER2-enriched & $4(2.9 \%)$ & $36(13 \%)$ & $2(6.5 \%)$ & \\
\hline Luminal A or Normal like & $78(57.4 \%)$ & $100(36.1 \%)$ & $13(41.9 \%)$ & \\
\hline Luminal B & $40(29.4 \%)$ & $60(21.7 \%)$ & $10(32.3 \%)$ & \\
\hline Pathological stage & & & & 0.599 \\
\hline Stage I & $25(18.4 \%)$ & $56(20.2 \%)$ & $8(25.8 \%)$ & \\
\hline Stage II & $82(60.3 \%)$ & $175(63.2 \%)$ & $16(51.6 \%)$ & \\
\hline Stage III & $29(21.3 \%)$ & $46(16.6 \%)$ & $7(22.6 \%)$ & \\
\hline
\end{tabular}

$P$ values were estimated using Fisher's exact or the chi-square test.

HER2: human epidermal growth factor receptor 2. 


\begin{tabular}{|lllll|}
\hline Variables & $\begin{array}{l}\text { Controls, } \\
\mathbf{n = 1 3 6}\end{array}$ & $\begin{array}{l}\text { Low-risk, } \\
\mathbf{n = 2 7 7}\end{array}$ & $\begin{array}{l}\text { High-risk, } \\
\mathbf{n = 3 1}\end{array}$ & $P$ \\
\hline Treatment & & & & \\
\hline Radiation & $75(55.1 \%)$ & $151(54.5 \%)$ & $17(54.8 \%)$ & 0.993 \\
\hline Pharmaceutical & $118(86.8 \%)$ & $225(81.2 \%)$ & $20(64.5 \%)$ & $\mathbf{0 . 0 1 4}$ \\
\hline All-cause mortality & $4(2.9 \%)$ & $7(2.5 \%)$ & $5(16.1 \%)$ & $\mathbf{0 . 0 0 6}$ \\
\hline P values were estimated using Fisher's exact or the chi-square test. & \\
\hline HER2: human epidermal growth factor receptor 2. & & \\
\hline
\end{tabular}

Table 4 presents the results of the Cox proportional hazard regression analysis for overall survival. The effect of group category (control, low risk, or high risk) and known prognostic factors (i.e., age group, molecular subtypes, pathologic stages, and treatment characteristics) on overall survival were analyzed. Compared with controls, the high-risk group had a significantly higher risk of poor overall survival. The estimated hazard ratios were $9.60(95 \% \mathrm{Cl}=2.43-37.96, P=0.001)$ and $9.94(95 \% \mathrm{Cl}=2.24-44.20, P=$ 0.003 ) in the univariate and multivariate models, respectively. The low-risk group did not have a significantly higher risk of poor overall survival than did controls. 
Table 4

Cox proportional hazard regression analysis for overall survival in patients with early-stage IDC breast cancer.

\begin{tabular}{|c|c|c|c|c|}
\hline Variables & Crude-HR (95\%Cl) & $P$ & Adjusted-HR (95\% Cl) & $P$ \\
\hline \multicolumn{5}{|l|}{ Gene mutation risk subgroup } \\
\hline Controls & Ref & & Ref & \\
\hline Low-risk & $1.17(0.34-4.07)$ & 0.801 & $1.01(0.25-4.05)$ & 0.993 \\
\hline High-risk & $9.60(2.43-37.96)$ & 0.001 & $9.94(2.24-44.20)$ & 0.003 \\
\hline \multicolumn{5}{|l|}{ Age group (years) } \\
\hline$<35$ & Ref & & Ref & \\
\hline $35-50$ & $0.20(0.02-1.97)$ & 0.166 & $0.28(0.02-3.30)$ & 0.313 \\
\hline$>50$ & $0.54(0.07-4.24)$ & 0.560 & $0.54(0.06-5.21)$ & 0.593 \\
\hline \multicolumn{5}{|l|}{ Subtypes } \\
\hline Luminal A or Normal like & Ref & & Ref & \\
\hline Luminal B & $2.82(0.77-10.34)$ & 0.118 & $1.76(0.44-7.04)$ & 0.422 \\
\hline HER2-enriched & $3.59(0.83-15.60)$ & 0.088 & $3.66(0.70-18.99)$ & 0.123 \\
\hline Basal-like & $1.30(0.31-5.50)$ & 0.722 & $1.14(0.24-5.33)$ & 0.872 \\
\hline \multicolumn{5}{|l|}{ Pathological stage } \\
\hline Stage I & Ref & & Ref & \\
\hline Stage II & $4.06(0.52-31.82)$ & 0.183 & $6.58(0.67-64.22)$ & 0.105 \\
\hline Stage III & $5.56(0.62-50.28)$ & 0.127 & $9.04(0.75-109.58)$ & 0.084 \\
\hline \multicolumn{5}{|l|}{ Treatment } \\
\hline $\begin{array}{l}\text { Radiation vs. without } \\
\text { radiation }\end{array}$ & $0.75(0.28-2.03)$ & 0.577 & $0.58(0.19-1.76)$ & 0.336 \\
\hline $\begin{array}{l}\text { Pharmaceutical vs. without } \\
\text { pharmaceutical }\end{array}$ & $0.33(0.10-1.07)$ & 0.065 & $0.39(0.11-1.40)$ & 0.151 \\
\hline
\end{tabular}

\section{Discussion}


This study adopted an integrative approach in the identification of candidate genes for risk assessment of overall survival in patients with early-stage breast cancer. Mutations in the 10 candidate genes were used to identify the patient group with a higher risk of poor overall survival. These 10 genes mostly participate in cell-cycle processes, DNA repair, and drug resistance.

BIRC5 (baculoviral IAP repeat containing 5) is amplified in $15-30 \%$ cases of breast cancers. It is involved in the prevention of apoptotic cell death through negatively regulating inhibitor of apoptosis proteins and has been indicated as an independent prognostic factor in breast cancer $[19,20]$. NOTCH1 (Notch homolog 1) is a protein coding gene contributes to multiple cellular processes, including cell differentiation, proliferation, and survival [21]. High expression of NOTCH1 may induce breast carcinoma and is strongly associated with poor prognosis and survival outcomes in breast cancer [14, 22]. MLH1 and $M S H 2$ are mismatch repair genes involved in repairing DNA replication errors. Defects in $M L H 1$ can contribute to breast cancer progression [23].

CCND1 (B-cell leukemia/lymphoma 1) is amplified in approximately $15 \%$ cases of breast cancers and is strongly associated with the expression of estrogen receptors, particularly in node-positive breast cancer [24]. In addition, the coamplification of CCND1 and EMSY (BRCA2-interacting transcriptional repressor) is associated with poor treatment outcome in ER-positive breast cancer [25]. ESR1 (estrogen receptor 1) encodes ER alpha, an estrogen receptor, and is amplified in $5-10 \%$ of breast cancers $[12,26]$. The overexpression of ER alpha protein could be used as a prognostic factor for ER-positive breast cancer and is predictive of endocrine therapy responsiveness [27]. SRC [V-Src Avian Sarcoma (Schmidt-Ruppin A-2) Viral Oncogene Homolog] encodes the non-receptor protein tyrosine kinase, which plays a role in the regulation of cell proliferation, migration, and survival [28]. The SRC mutation is known to be involved in malignant progression $[29,30]$. Increased SRC activation is correlated with trastuzumab resistance and interacts with estrogen receptors. Therefore, the combined use of SRC inhibitors has been suggested to overcome drug resistance in specific breast cancers [31].

HRAS (Harvey rat sarcoma viral oncogene homolog) and KRAS (Kirsten rat sarcoma 2 viral oncogene homolog) are oncogenes in the RAS family and are involved in $0-10 \%$ of breast cancers. RAS mutations are typically associated with poor survival; one study found that patients with RAS mutations had worse survival [32]. The intracellular actions mediated by IGF1R (insulin-like growth factor 1 receptor) are also involved in RAS signaling pathways [33]. IGF1R is a receptor with tyrosine kinase activity and its expression is associated with tumorigenesis [33]. Moreover, IGF1R overexpression is more common in ERpositive breast cancer. IGF1R expression is generally low in the HER2-enriched subtype and is heterogeneous in the basal-like subtype [33]. In addition, IGF1R may be used as an alternative therapeutic target for HER2-enriched, trastuzumab-resistant, or basal-like breast cancer [34, 35].

According to the past studies, the candidate genes are generally involved in breast cancer progression. Some are related to drug resistance in specific subtypes. Disease progression and drug resistance are commonly associated with poor overall survival due to the uncontrollable nature of cancer cells [36-38]. This study had several limitations. The retrospective nature of this study prevented the inclusion of 
certain covariates that might be associated with overall survival. Despite this, we have included information on the baseline demographic, tumor characteristics, molecular subtypes, and treatment characteristics used in most breast cancer studies. In addition, we included only patients with early-stage IDC breast cancer; therefore, the generalizability of our findings is limited to this subpopulation.

\section{Conclusion}

This study used integrated survival analysis to identify candidate genes in a group of patients with earlystage IDC breast cancer at high risk for poor survival outcomes and achieve further understanding of the effects of their gene mutation profiles on overall survival. The candidate genes are particularly involved in cell-cycle processes, DNA repair, and drug resistance, and their mutations are generally associated with disease progression or therapeutic resistance, which are commonly associated with poor survival outcomes. Future studies should investigate the integrative functionality of candidate genes in breast cancer further. Moreover, the combined use of machine learning algorithms should be the focus of further research on the nonlinear or high-order interaction effects between clinicopathological variables and the involved genes.

\section{Abbreviations}

IDC

Invasive ductal carcinoma; HER2:human epidermal growth factor receptor 2; DNA:deoxyribonucleic acid; HR:hazard ratio; Cl:confidence interval; Ref:Reference.

\section{Declarations}

\section{Ethics approval and consent to participate}

Not applicable

\section{Consent for publication}

Not applicable

\section{Availability of data and materials}

https://portal.gdc.cancer.gov/projects/TCGA-BRCA

\section{Competing interests}

The authors declare that they have no competing interests.

\section{Funding}

This work was supported by grants from the E-Da Cancer Hospital (EDCHT109009). 


\section{Authors' contributions}

$\mathrm{C}-\mathrm{CH}$ and $\mathrm{S}-\mathrm{HM}$ and drafted the manuscript. $\mathrm{C}-\mathrm{CH}$ and $\mathrm{H}-\mathrm{IH}$ were responsible for the data processing and interpretation. $\mathrm{H}-\mathrm{IH}$ and S-HM performed statistics analyses. S-HM conceived and designed the study and fully revised the final manuscript. All authors read and approved the final manuscript.

\section{Acknowledgements}

This work was supported by E-Da Cancer Hospital.

\section{References}

1. Goh CW, Wu J, Ding S, Lin C, Chen X, Huang O, Chen W, Li Y, Shen K, Zhu L. Invasive ductal carcinoma with coexisting ductal carcinoma in situ (IDC/DCIS) versus pure invasive ductal carcinoma (IDC): a comparison of clinicopathological characteristics, molecular subtypes, and clinical outcomes. J Cancer Res Clin Oncol. 2019;145(7):1877-86.

2. Kelemen G, Farkas V, Debrah J, Ormandi K, Voros A, Kaizer L, Varga Z, Lazar G, Kahan Z. The relationship of multifocality and tumor burden with various tumor characteristics and survival in early breast cancer. Neoplasma. 2012;59(5):566-73.

3. Yang SX, Polley EC: Systemic treatment and radiotherapy, breast cancer subtypes, and survival after long-term clinical follow-up. Breast cancer research and treatment 2019, 175(2):287-295.

4. Xiao Q, Zhou Y, Winter S, Buttner F, Schaeffeler E, Schwab M, Lauschke VM. Germline variant burden in multidrug resistance transporters is a therapy-specific predictor of survival in breast cancer patients. Int J Cancer. 2020;146(9):2475-87.

5. Ding S, Wu J, Lin C, Chen W, Li Y, Shen K, Zhu L. Predictors for Survival and Distribution of 21-Gene Recurrence Score in Patients With Pure Mucinous Breast Cancer: A SEER Population-Based Retrospective Analysis. Clin Breast Cancer. 2019;19(1):e66-73.

6. Christgen M, Bartels S, Radner M, Raap M, Rieger L, Christgen H, Gluz O, Nitz U, Harbeck N, Lehmann $\mathrm{U}$, et al. ERBB2 mutation frequency in lobular breast cancer with pleomorphic histology or high-risk characteristics by molecular expression profiling. Genes Chromosomes Cancer. 2019;58(3):175-85.

7. Figg IIWD, Reid J. Monitor tumor burden with circulating tumor DNA. Cancer Biol Ther. 2013;14(8):697-8.

8. Al-Kuraya K, Schraml P, Torhorst J, Tapia C, Zaharieva B, Novotny H, Spichtin H, Maurer R, Mirlacher $\mathrm{M}$, Kochli $\mathrm{O}$, et al. Prognostic relevance of gene amplifications and coamplifications in breast cancer. Cancer Res. 2004;64(23):8534-40.

9. Jovanovic J, Ronneberg JA, Tost J, Kristensen V. The epigenetics of breast cancer. Mol Oncol. 2010;4(3):242-54.

10. Carcangiu ML, Casalini P, Ménard S. Breast tumors: an overview. Atlas of Genetics and Cytogenetics in Oncology and Haematology 2005. 
11. Kirkegaard T, Nielsen KV, Jensen LB, Campbell FM, Muller S, Tovey SM, Brown S, Cooke TG, Bartlett JM. Genetic alterations of CCND1 and EMSY in breast cancers. Histopathology. 2008;52(6):698705.

12. Holst F, Stahl PR, Ruiz C, Hellwinkel O, Jehan Z, Wendland M, Lebeau A, Terracciano L, Al-Kuraya K, Janicke $F$, et al. Estrogen receptor alpha (ESR1) gene amplification is frequent in breast cancer. Nat Genet. 2007;39(5):655-60.

13. Curtis C, Shah SP, Chin SF, Turashvili G, Rueda OM, Dunning MJ, Speed D, Lynch AG, Samarajiwa S, Yuan $Y$, et al. The genomic and transcriptomic architecture of 2,000 breast tumours reveals novel subgroups. Nature. 2012;486(7403):346-52.

14. Hu YY, Zheng MH, Zhang R, Liang YM, Han H. Notch signaling pathway and cancer metastasis. Adv Exp Med Biol. 2012;727:186-98.

15. Garcia JM, Silva J, Pena C, Garcia V, Rodriguez R, Cruz MA, Cantos B, Provencio M, Espana P, Bonilla F. Promoter methylation of the PTEN gene is a common molecular change in breast cancer. Genes Chromosomes Cancer. 2004;41(2):117-24.

16. Driscoll JJ, Rixe O. Overall survival: still the gold standard: why overall survival remains the definitive end point in cancer clinical trials. The Cancer Journal. 2009;15(5):401-5.

17. Motakis E, Ivshina AV, Kuznetsov VA. Data-driven approach to predict survival of cancer patients: estimation of microarray genes' prediction significance by Cox proportional hazard regression model. IEEE Eng Med Biol Mag. 2009;28(4):58-66.

18. Zare A, Mahmoodi M, Mohammad K, Zeraati H, Hosseini M, Holakouie Naieni K. A comparison between Kaplan-Meier and weighted Kaplan-Meier methods of five-year survival estimation of patients with gastric cancer. Acta Med Iran. 2014;52(10):764-7.

19. Davis LM, Harris C, Tang L, Doherty P, Hraber P, Sakai Y, Bocklage T, Doeden K, Hall B, Alsobrook J, et al. Amplification patterns of three genomic regions predict distant recurrence in breast carcinoma. J Mol Diagn. 2007;9(3):327-36.

20. Brennan DJ, Rexhepaj E, O'Brien SL, McSherry E, O'Connor DP, Fagan A, Culhane AC, Higgins DG, Jirstrom K, Millikan RC, et al. Altered cytoplasmic-to-nuclear ratio of survivin is a prognostic indicator in breast cancer. Clin Cancer Res. 2008;14(9):2681-9.

21. Reedijk M. Notch signaling and breast cancer. Adv Exp Med Biol. 2012;727:241-57.

22. Han J, Hendzel MJ, Allalunis-Turner J. Notch signaling as a therapeutic target for breast cancer treatment? Breast Cancer Res. 2011;13(3):210.

23. Malik SS, Zia A, Mubarik S, Masood N, Rashid S, Sherrard A, Khan MB, Khadim MT. Correlation of MLH1 polymorphisms, survival statistics, in silico assessment and gene downregulation with clinical outcomes among breast cancer cases. Mol Biol Rep. 2020;47(1):683-92.

24. Jensen LB, Bartlett JM, Witton CJ, Kirkegaard T, Brown S, Muller S, Campbell F, Cooke TG, Nielsen KV. Frequent amplifications and deletions of G1/S-phase transition genes, CCND1 and MYC in early breast cancers: a potential role in G1/S escape. Cancer Biomark. 2009;5(1):41-9. 
25. Brown LA, Johnson K, Leung S, Bismar TA, Benitez J, Foulkes WD, Huntsman DG. Co-amplification of CCND1 and EMSY is associated with an adverse outcome in ER-positive tamoxifen-treated breast cancers. Breast Cancer Res Treat. 2010;121(2):347-54.

26. Holst F, Moelans CB, Filipits M, Singer CF, Simon R, van Diest PJ. On the evidence for ESR1 amplification in breast cancer. Nat Rev Cancer. 2012;12(2):149.

27. Romond EH, Perez EA, Bryant J, Suman VJ, Geyer CE Jr, Davidson NE, Tan-Chiu E, Martino S, Paik S, Kaufman PA, et al. Trastuzumab plus adjuvant chemotherapy for operable HER2-positive breast cancer. N Engl J Med. 2005;353(16):1673-84.

28. Zhang S, Huang WC, Li P, Guo H, Poh SB, Brady SW, Xiong Y, Tseng LM, Li SH, Ding Z, et al. Combating trastuzumab resistance by targeting SRC, a common node downstream of multiple resistance pathways. Nat Med. 2011;17(4):461-9.

29. Yao M, Fang W, Smart C, Hu Q, Huang S, Alvarez N, Fields P, Cheng N. CCR2 Chemokine Receptors Enhance Growth and Cell-Cycle Progression of Breast Cancer Cells through SRC and PKC Activation. Mol Cancer Res. 2019;17(2):604-17.

30. Roseweir AK, Powell A, Horstman SL, Inthagard J, Park JH, McMillan DC, Horgan PG, Edwards J. Src family kinases, $\mathrm{HCK}$ and FGR, associate with local inflammation and tumour progression in colorectal cancer. Cell Signal. 2019;56:15-22.

31. Mayer EL, Krop IE. Advances in targeting SRC in the treatment of breast cancer and other solid malignancies. Clin Cancer Res. 2010;16(14):3526-32.

32. Tokumaru Y, Oshi M, Katsuta E, Yan L, Satyananda V, Matsuhashi N, Futamura M, Akao Y, Yoshida K, Takabe K. KRAS signaling enriched triple negative breast cancer is associated with favorable tumor immune microenvironment and better survival. Am J Cancer Res. 2020;10(3):897-907.

33. Bhargava R, Beriwal S, McManus K, Dabbs DJ. Insulin-like growth factor receptor-1 (IGF-1R) expression in normal breast, proliferative breast lesions, and breast carcinoma. Appl Immunohistochem Mol Morphol. 2011;19(3):218-25.

34. Jin Q, Esteva FJ. Cross-talk between the ErbB/HER family and the type I insulin-like growth factor receptor signaling pathway in breast cancer. J Mammary Gland Biol Neoplasia. 2008;13(4):485-98.

35. Klinakis A, Szabolcs M, Chen G, Xuan S, Hibshoosh H, Efstratiadis A. Igf1r as a therapeutic target in a mouse model of basal-like breast cancer. Proc Natl Acad Sci U S A. 2009;106(7):2359-64.

36. Lim HS, Sun W, Parivar K, Wang D. Predicting Overall Survival and Progression-Free Survival Using Tumor Dynamics in Advanced Breast Cancer Patients. AAPS J. 2019;21(2):22.

37. Minchin RF, Butcher NJ. Trimodal distribution of arylamine N-acetyltransferase 1 mRNA in breast cancer tumors: association with overall survival and drug resistance. BMC Genom. 2018;19(1):513.

38. Liu Y, Yu C, Wu Y, Sun X, Su Q, You C, Xin H. CD44(+) fibroblasts increases breast cancer cell survival and drug resistance via IGF2BP3-CD44-IGF2 signalling. J Cell Mol Med. 2017;21(9):1979-88.

\section{Figures}




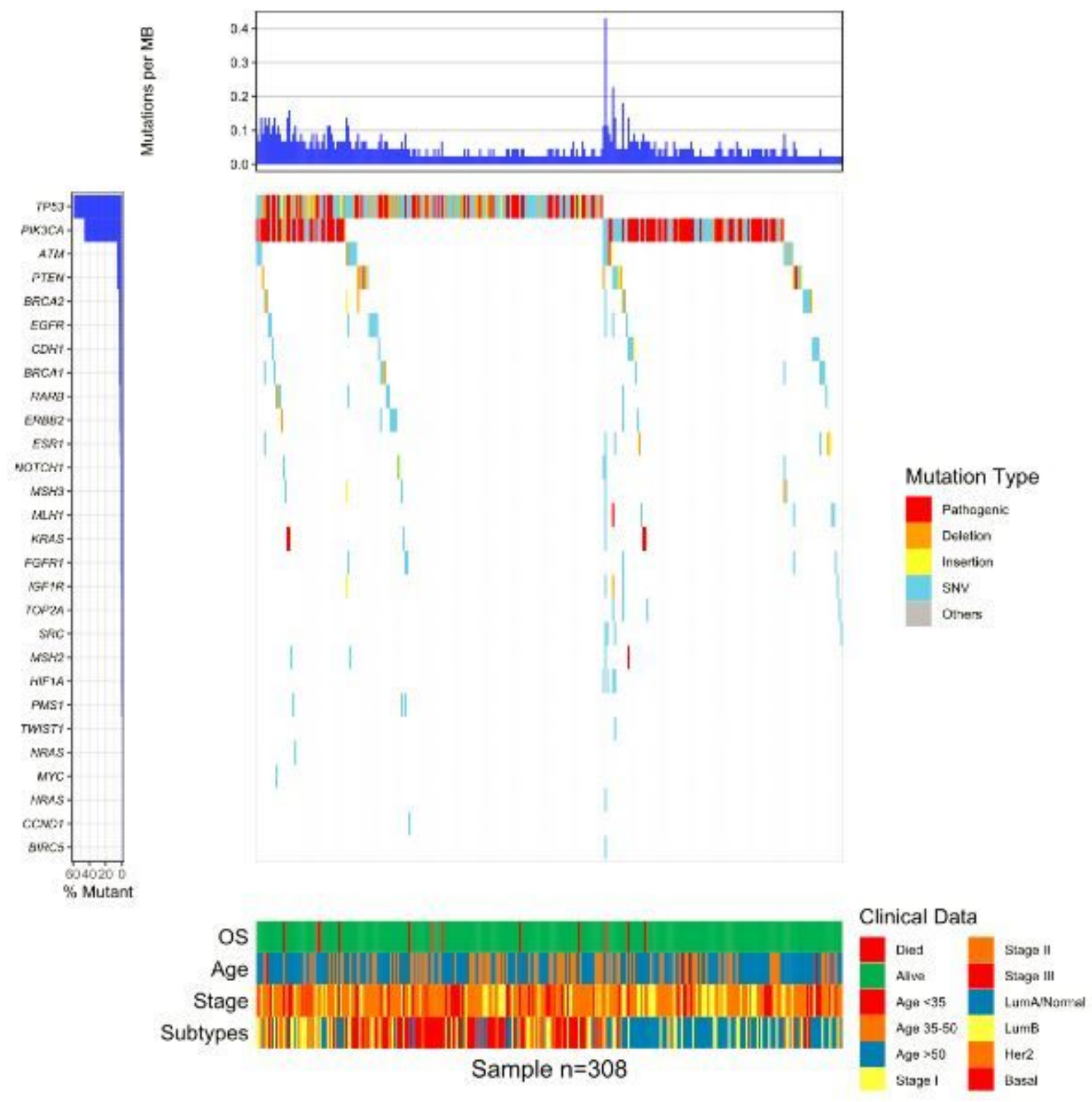

Figure 1

Gene mutation profiles and clinical features of early-stage IDC breast cancer. 

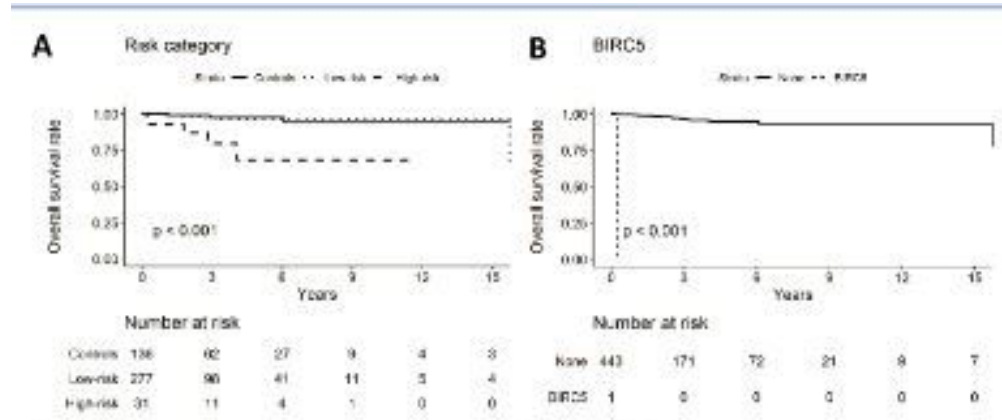

C COND1

D ESRI

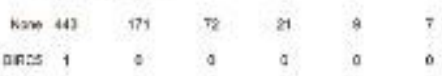

E Has

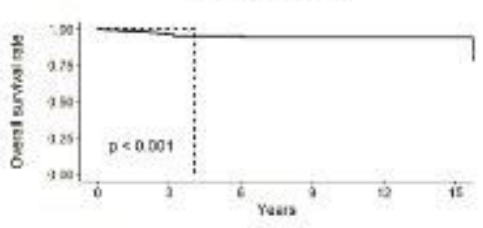

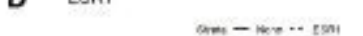
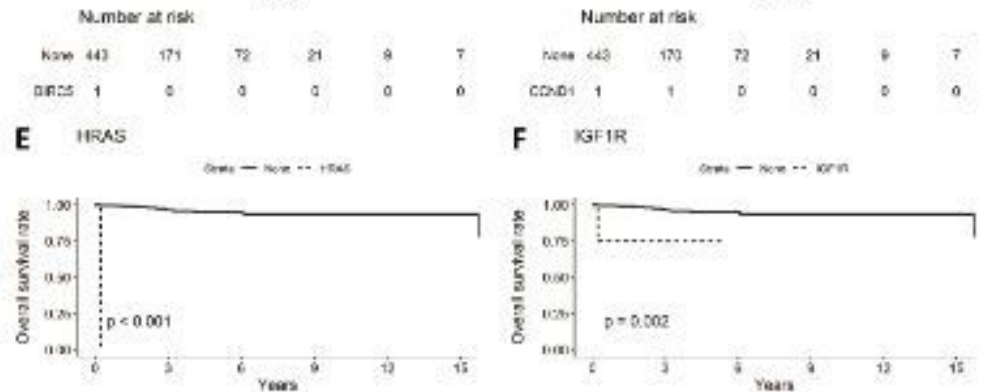

F $\quad$ KG 1 R



N.mber at risis

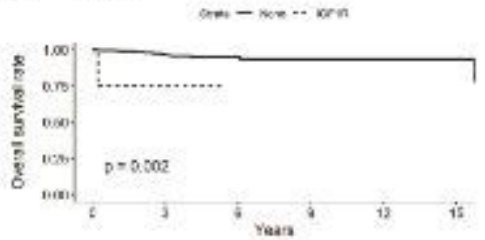

Number misk


Number at nisk

G KRess

ines 1

H Mui1
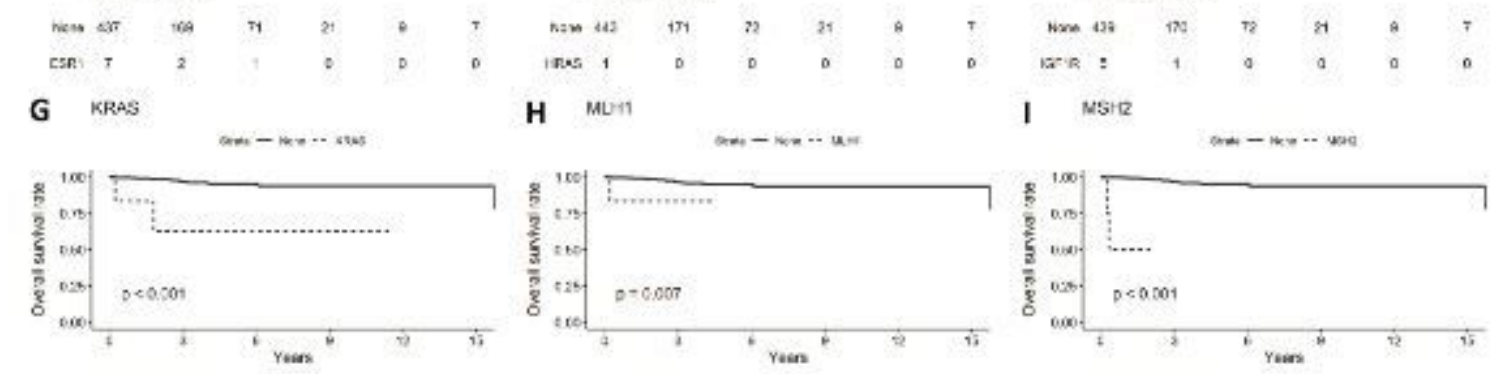

I MSir

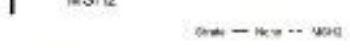

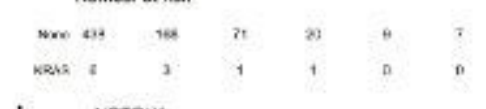

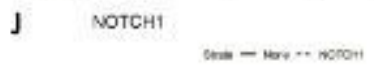

$$
\text { K } \sec
$$

Numecrat riak

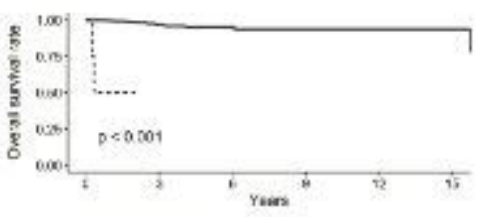

are

wa.e
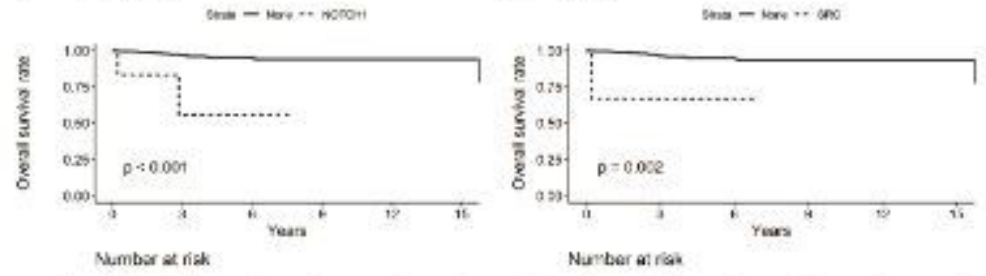

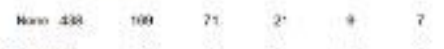

Numbar at rak

num eat

метсин

\section{Figure 2}

Kaplan-Meier plot of overall survival in patients with early-stage IDC breast cancer according to (a) gene mutation risk groups and (b) - (k) single gene mutation status. 